\title{
New Aesthetic Characteristics Emerging in the Digital Cinema Era
}

\author{
Changhai Chen ${ }^{1, \text { a }}$ \\ ${ }^{1}$ College of Art Graduate School, University of Glasgow, Glasgow, G12 8QQ, United Kingdom \\ a2666206c@student.gla.ac.uk
}

\begin{abstract}
Digital film technology has constantly transformed and enhanced the fundamental aesthetic elements in the traditional aesthetic categories of film aesthetics during its gradual penetration into the film art system, enabling these fundamental aesthetic elements to take on new forms and appearances that enrich the artistic communication of film and mark This is a sign of artistic advancement. The fusion of old and new technologies in synergy with the original film system has also accelerated the development of digital film technology as an aesthetic model, and in adapting to the original film art system, digital film aesthetics has produced aesthetic implications that transcend the original system, in terms of virtual images, spatial and temporal concepts, narrative modes, sound and picture relationships, and movement characters. They all exhibit new aesthetic characteristics that are distinct from traditional film aesthetics in terms of virtual images, spatial and temporal concepts, narrative modes, sound and image relationships, movement characteristics, and interactive methods. When one examines existing discussions on digital cinema in China and globally, it is easy to see that they primarily focus on expanding the audiovisual expression of images and on the study of the expressive power and image effects of digital special effects, while research on expanding film concepts and expanding film aesthetics is superficial, or even nonexistent. From a film aesthetics standpoint from the standpoint of film aesthetics, as digital technology has gradually displaced traditional modes of film production and concepts, audience viewing styles, and human aesthetic concepts, the aesthetics of digital film under the new digital technology can be a new construction in terms of time and space, reality, narrative techniques, virtual reality, and aesthetic acceptance. Based on established film theories and aesthetic notions, this study will seek to develop film aesthetics in the digital era, highlighting the study's uniqueness and systemic character in light of shifting aesthetic categories and the incorporation of new aspects in digital cinema.
\end{abstract}

Keywords: Digital cinema, Digital image, Aesthetic characteristics, Cinema spectacle.

\section{A Critical Examination of the Digital Cinema Spectacle}

When a new art form is created, determining its artistry is always a contentious issue. Whether the digital image possesses independent artistic qualities or not, it has made an indelible contribution to the development of video art's expressive power. Digital images' primary manifestation in cinema is visual effects, which enable the creation of visual spectacles previously unattainable in the film era. As a result, studying digital images through the lens of visual spectacle or spectacle theory is a critical area of research for digital cinema. Geoff King (2000) examines digital effects and virtual scenes in contemporary Hollywood blockbusters In his book, focusing on the under-researched dynamic relationship between narrative and spectacle in order to demonstrate visual spectacle's "invisible narrative" function, noting that this invisible narrative mode is "The resurrection of the 'pioneering myth'. Scott Bukatman argues in his thesis (1995) that the sense of the sublime in special effects sequences such as Close Encounters of the Third Kind and 2001: A Space Odyssey is a continuation and inheritance of the American art historical view of nature. He elaborates this in terms of humanistic traditions, lending historical weight to digital special effects. Additionally, Tom Gunning's proposal for a 'film of attraction' (1986) is a critical guide for the study of spectacle narratives in the digital age, and his analysis of early films suggests that the 'film of attraction' focuses on the spectacle's aesthetics. He argues, through his analysis of early films, that "attractive cinema" highlights the "exhibitionism" of spectacle over narrative's "representationalism." His analysis of the explosive and surprising nature of visual communication and audience perception in early "attractive cinema" is consistent with contemporary theories of spectacle, and is founded on the so-called "directionless" temporality of early "attractive cinema" as a foundation for cinematic representation. The summary of cinematic expressiveness based on the so-called "directionless" temporality of early "attractive cinema" also enables us to study the artistic communication of the digital spectacle in the modern era.

With the release of films such as "The Matrix," "Lola rennt," "Harry Potter," and "The Hobbit," people are exposed to the fast-paced virtual time and space changes and aesthetic breakthrough of the transcendental world, and new aesthetic forms such as "virtual aesthetics," "digital aesthetics," and "techno-aesthetics" are being advanced as distinct aesthetic concepts in the digital age. In the digital age, new forms of aesthetics such as "virtual aesthetics," "digital aesthetics," and "techno-aesthetics" have been proposed as distinct aesthetic concepts and are becoming increasingly prevalent in scholars' research horizons. Marc Furstenau (2003) argues in his dissertation that digital technology has created a conflict between structuralism and film semiotics in the study of cinema's ontology, causing scholars to question the authenticity of digital images and to be more interested in the relationship between reality and images than in the logical correlation between images in the representation of reality and images. Indeed, we must consider the aesthetic construction of film culture as a whole, as well as its communication and dissemination, from image reality to its 
technical properties. On the other hand, Lev Manovich's (2001) work departs from the reproductive reality of the traditional image to elaborate on the unique characteristics of new media, emphasising its capacity to reflect reality in its representation and the artistic impact it has on the viewer, i.e. connecting visual reality to aesthetic features, but without developing a specific analysis of the digital image's aesthetic perceptual activity. The article by Adam Ganz (2006), discusses the impact of digital cinema on film practise and aesthetics, positioning digital cinema as a new way of thinking about cinema based on film technology, recognising how the new era of cinema is altering the relationship between director, actor, and audience, and examining the uniqueness of narrative structure, performance, and image. Bery Gaut (2010) attempts to establish a critical foundation for the digital image through the lens of classical aesthetic theory in his book. Each chapter of the book is devoted to a different aspect of the digital image. His study, however, confines the digital image to the framework of classical film theory and misses the mark when it comes to the image's uniqueness and relationship to computers and multimedia. Francesco Casetti (2015) argues in his book that the transformation of contemporary cinema aims to adaption and reposition cinema's production and distribution in order to achieve a new interpretation of cinema, examining how the cinematic experience can be reborn through technological rethinking and how new cinematic experiences can be created. Alistair Swale (2015) attempts to discuss the aesthetics of animation in the context of digital cinema in his paper. He focuses on the essential qualities of the visual representation or experiential experience of the moving image in the 'postphotographic' or 'post-cinema' era, overcoming the paradoxes inherent in digital film studies in order to explore the accepted expressions and aesthetic meanings of contemporary cinema through the use of virtual reality. It examines how cinema's language has resulted in the screen's transformation from a 'window' to a 'portal,' trying to emphasize the shift in perceptions of narrative conventions, character psychology, and aesthetic reception.

The aforementioned achievements in the study of digital cinema reveal a hidden issue: the study of film aesthetics in the context of contemporary digital technology has not been consolidated, or a systematic aesthetic construction for the overall creative experience of digital cinema technology has not been developed. According to the research conducted thus far, the industry has not yet defined the field of digital technology definitively, the influence of digital technology continues to grow, and the artistic expressiveness of digital cinema is still being explored by the film industry. However, resolving technical issues does not imply resolving artistic issues. The resolution of technical issues is necessary but not sufficient for the exploration of artistic issues, which is why there has been no comprehensive and systematic aesthetics of digital cinema in the last two decades.

To address this issue, this paper will examine the new aesthetic characteristics of digital cinema as a result of the new digital technological environment. It will examine the new aesthetic characteristics of digital cinema in terms of virtual images, spatio-temporal concepts, narrative modes, sound and image relationships, movement characteristics, and interactive methods: the richness of virtual images, the conceptualization of digital situations, the versatility of mimetic styles, and the experiential nature of physical touch are all used to investigate the mimetic nature of virtual images; the transcendence of virtual space, the digital transformation of simultaneous arrays of time, long shots, and montages.

\section{The Shape of Imitation: The Anthropomorphism of the Digital Virtual Image}

Virtual pictures are the most visible technical development and expression of digital technology in the creation of film art. On the one hand, the ease with which producers can convert imaginary life into digital visuals is aided by the convenience of digital creation. The film's visual effect can be adapted to the plot's requirements. In terms of creating context, image presentation, and action performance to show the film's theme, digital mimicry, on the other hand, can reflect a better viewing experience than traditional visuals. Digital video's natural scenery, characters, and plot scenes are all more conducive to the film's narrative and plot development, as well as evoking emotional resonance in the spectator. We can investigate the visual presentation and aesthetic characteristics of digital mimicry on four levels from the standpoint of artistic expression of digital cinema images: the image body of the virtual image, the visual representation of the mimic reality, the stylized representation of digital mimicry, and the interactive context of virtual reality.

\subsection{Mimicry of the Image Dimension: The Richness of the Digital "Image Body}

Human art is concerned with the body, and film is the art of moulding the body. The design of the image body of a digital character, as well as the simulation of a digital character or the production of an image of a distinctive creature, are all examples of virtual images. Such digital character bodies, in general, necessitate creative imaginative modelling or the ability to follow actual figurative reductions, and must be made digitally in accordance with the character's attributes or true existence. The character's physical form, expressions and movements, and personality are all important components in determining the image body of the digital character. " The body as a cinematic language, which is both an ideational language and a vehicle for the entire 'human' in and of itself, has both a practical and natural aesthetic value. The latter is referred to as the 'everyday body,' whereas the body as a cinematic ideographic usage is referred to as the 'performance body.' The 'performing body' is the body that is used in cinematic depiction. In the case of an actor, the two are one 'body,' yet they are frequently at variance with and even at odds with each other ". The classic cinematic body method refers to the actor's body transitioning from the "everyday body" to the "acting body" to the "video body" until the 'video body's aesthetic quality is complete." As a result, the "image body" and the "performance body" are essentially identical. The body strategy of digital cinema is separated into two situations: the first is an image with partial capture of real persons or expressions and movements, with the goal of achieving the best "match" possible between the "acting body" of real actors and the "virtual body" of digital characters." The relationship between the two is clear, resulting in a loss of convergence between the performing body and the virtual body, e.g. Gollum in The Lord of the Rings (2001), the Hulk, and Iron Man in The Avengers (2012) after being transformed in anger are all images of the performing body and the digital body. The other is a wholly virtual digital persona with no "everyday body," 
"performance body," or "performance body," but only a "video body." As in the case of the large digital audience watching the game on the dugout in The Secret in Their Eyes (2009), the digital tiger, the animal protagonist in Life of Pi (2013), Master Yoda in Star Wars (2002), and Transformers (2007), the shape-shifting robot in The Curious Case of Benjamin Button (2008), and the image of Barton as a young boy in The Curious Case of Benjamin Button (2008), the first two are submerged in the physical construction of the latter.

The digital 'image body,' which is devoid of the 'everyday body' and the 'performance body,' demonstrates the evolving nature of the image body in the digital age, as well as the digital 'image body' embodied by digital virtual characters. The realism of the digital "image body" is evident in both the image body's evolution in the digital age and the digital virtual characters that embody the digital "image body." This digital presence is indistinguishable from the film's objective reality, and the hyper-realistic visual experience of the digital characters is beyond the viewer's level of perception, resulting in a misinterpretation of the digital image, which further strengthens the viewer's identification with the virtual character, resulting in an unconscious 'deep attachment'. Of course, from the creator's perspective, the digital virtual body is more than a modelled physical simulacrum; it is an underlying perspective of human self-reflection, a unique mode of existence born out of the necessity of creating a film text and human qualities for self-reflection. The viewer interacts with these fictitious digital 'image bodies' in narrative contexts that elicit associated emotions and imaginative recognition, while observing a correlation between the imaginative expression of these digital bodies and their own emotional experience to a greater or lesser extent. Whether it is the body's incarnation as a sign or symbol, or the association of bodily attributes in biogenesis, cultural fields, and new media, the figurative visual symbol of the digital 'image body' signifies the richness of the digital image and the difference in identity, which are the connotative constructions that draw the viewer's attention to the body's imagery. For one thing, the virtual body's shaping results in a strong and realistic contagion of the image body. Virtual bodies in digital cinema are digitally synthesised or entirely created virtually, ranging from superheroes such as Iron Man and the Hulk, who employ a variety of synthesis techniques, to virtual stars such as the virtual tiger and Simone in the adolescent school, who are identical to reality, to steelintelligent alien creatures such as Transformers and Aliens, who appear in science fiction films. These virtual images, whether indistinguishable characters or visible fantasy bodies, immediately engage the viewer's senses with their concrete, graphic, and palpable body images, as Metz points out "Illusory art can only be justified if it is convincing (otherwise it devolves into absurdity), and unreal elements can only have power if they are made to appear real. This is distinct from the mental image created by some distorted illustrations "'. These virtual 'image bodies,' which are derived primarily from the creators' design manuscripts, miniatures, and computergenerated imagery simulations, are vibrant and distinctive, and the figurative form has proliferated on the screen, establishing itself as an effective vehicle for artistic beauty.

\subsection{The Imagination of A Fantastic Vision: The Conceptualization of A Digital Situation}

Digital mimicry typically represents parts that are impossible to achieve through traditional filming methods, preferring to represent the spatio-temporal state of alternative worlds that are significantly different from the times or reality in which we live, whether it is the restoration of an original world from the past, the realistic imagination of a parallel world, or the virtual construction of a future space-time, all of which can be seamlessly transformed into a typical spectacle, hallucination, or alienated scenography. The groundbreaking artistic communication and visual effect of this implausible and unconventional mode of imagery are most noticeable in the conception of digital mimesis. Digital technology has evolved into a medium for bridging the divide between reality and imagination. Film is a more tangible embodiment of the fantastic and a precise transformation of the fantastic into cinematic reality. Digital mimesis images are based on imaginative realities rather than objective realities, and are artistic realities elevated above real life rather than objective realities. In other words, digital mimicry allows for a more liberated reflection of real, tangible landscapes that do not exist in reality, and these extremely realistic and believable visuals highlight the simulated image's aesthetic significance. Whereas audiences in traditional cinema could distinguish between fiction and reality, as well as between the various fictional genres of cinema and the traditional set-up of special effects, in digital cinema, the increasing power of technology has begun to blur the line between the specific scenes in which special effects are used and the virtual composition of fantasy elements.

On the one hand, the conceptual nature of digital mimesis facilitates the emergence of a diverse array of visual symbols and their rhetorical significance. Artists can employ a variety of artistic techniques, including virtual modelling, deformation and exaggeration, conceptual abstraction, and symbolic analogy, to investigate the expression of digital mimesis, pushing the boundaries of hypotheticality and conceiving a new psychological reality within it. This method of representation underscores psychological experiences and illusions of consciousness, and expresses the filmmakers' imaginative experiences and values by altering the spatiotemporal form or appearance of the object to create a "virtual non-reality" on screen, or by providing a new perspective for expressing the construction of meaning for the multifaceted reality of the expanded possible world, thereby broadening the audience's perception.

To begin, the conceptualization of fantasy space and time produces an awe-inspiring spectacle. For instance, in Avatar (2009), the stunning fantasy space-time of the planet Pandora is conceived prominently, creating visual awe in the audience. The Matrix Reloaded (2003), in which a stream of digital symbols flows in front of Neo in the form of a rain screen of digital characters, symbolising people's digital state in the cyber world and the inherent relationship between humans and digital information. The Star Wars series' "holographic deck" models and the Harry Potter series' magical effects allow the audience to experience the strangeness of the virtual world and the shock of the magnificent spectacle. Second, digital reproduction encapsulates the process of visual symbolic meaning generation. If digital characters such as the digital tourists on each deck of the Titanic (1997), the 
thousands of digital magic soldiers on the battlefield in Lord of the Rings (2001), and the tens of thousands of digital battleships in the Star Wars prequel series reflect the sheer number of groups that can be reproduced digitally, by the time the reproduction techniques in Star Wars Prequels: Attack of the Clones (2002) have been perfected. When Smith in Black manifests as a virus in The Matrix (2003), the concept of infinite reproduction and symbolic meaning enters the narrative and establishes a new rhetoric of recurrence, demonstrating the regenerative power of digital reproduction. Once again, the digital image becomes more figurative in its symbolic imagery, exhibiting a palpable and palpable surrealist tendency. Surrealism "seeks to manifest itself in some concrete way, to accept what is imaginable within the realm of reality." Digital mimesis transforms this concrete form into a 'visible object' and a decipherable representation, preserving the sensible form's aesthetics through rhetorical devices such as symbolism or metaphor.

On the other hand, the spectacle of digital nature and situations is envisioned as a manifestation of the sublime's beauty. The British philosopher Edmund Burke describes the sublime as being physically and psychologically distinct from empirical descriptions of beauty, summing up its characteristics as 'terror', 'ambiguity', 'power', 'emptiness', 'vastness', 'infinity', and 'grandeur'. "voidness," "vastness," "infinity," and "grandeur" are all attributes of the sublime. On the basis of Edmund Burke, Kant positions the sublime alongside beauty as an aesthetic judgement, highlighting the sublime's 'formlessness,' i.e. the 'infinity of quantity' and 'power,' revealing that the sublime is The aesthetic significance of the sublime is found in the human spirit's greatness when it overcomes the psychological perception of the sublime as unavoidable. While it is natural for humans to experience a sense of the sublime in natural settings such as the sea and mountains, the reality depicted in digital contexts is frequently a spectacle of nature that transcends human cognition, and it is easy to conclude from both empirical and rational cognitive perspectives that digital spectacles can transcend people's habitual cognition and aesthetic experience, and that audiences experience a stronger sense of the sublime than they do when they are actuated. In the digital age, digital contexts have become a new tool for filmmakers, enabling them to design shapes and construct objects, to translate their artistic imagination of the existence of possible worlds into reality, or to create digital nature in a diffuse figurative space to express poetic imagery, multiple perceptions, or abstract thinking. Digital nature is not an objective and real natural environment, but a mathematical representation or mechanical embodiment of natural things with infinite forms or powers, which can be portrayed as an apocalyptic disaster, a paradise in a worldly wonderland, a mysterious and ambiguous space, or a vast and infinite universe, such as the fantastically beautiful city in the sea in Aquaman (2018), the telescopic and bizarre folding space in Doctor Strange (2016), or the vast and infinite universe in Avatar (2009), the sublime beauty of digital nature is reflected in digital representations, which expand the audience's perception of possible worlds or extreme spaces and provide aesthetic pleasure. For instance, in The Day After Tomorrow (2004), the audiovisual experience of a realistic and spectacular disaster intensifies the audience's inner fear of being powerless in the face of an overwhelming natural disaster. The spatial pressure of grandeur or threatening oppression implied by digital nature is a representation based on hypothesis, as Kant states: "The more frightening and attractive the sights are, the more sublime we call them, if we are in a safe place, because they raise our mental powers above the usual scale and enable us to discover another resistance within ourselves that gives us the courage to confront the illusion of nature's almighty power." The more difficult it is for the viewer to overcome the sublime sense of power or numbers generated by digital nature, the more profoundly the "spiritual greatness" that emerges when the plot or characters overcome digital nature or accomplish their task emerges. The spectacle of digital imagery has always pushed the human eye to its limits, transcending sensory experience and psychological perception and leading the viewer to the sublime beauty of the mind through a constant advancement in digital spectacle.

\subsection{Digital Representation of Anthropomorphism: The Versatility of Digital Style}

With the advent of digital technology, a series of media transformations occurred, ranging from filming equipment to storage media. Although digital images created directly through virtual computer filming and computer graphics are no longer a true record of objective reality and scene reproduction, or are significantly different from real life or the original appearance of things, their ability to create a sense of reality is clearly more mature, as conditions for artistic image processing and presentation of image reality have developed. Digital expression is abundant and diverse, exhibiting a variety of digital styles. The artistic realism on display leaves no doubt in the viewer's mind, or the viewer clearly feels that this 'hyper-real' expression transcends reality without compromising the image representation's authenticity. For starters, the strong heterogeneity inherent in digital collage results in the creation of a truly unique digital style and artistic expression. Through the use of digital collage, deliberate split screen, high-speed photography, slow upscaling, digital modelling, and other digital technologies, digital cinema creates a variety of digital styles. On the one hand, collage and synthesis in digital environments have facilitated the emergence of new modes of artistic expression. Beginning with The Matrix (1999), the slow mode created by high-speed photography and collage compositing effects has become a necessary skill in the slow-motion genre, evolving into a fully accepted mimetic modelling device that has gradually made this spectacle shockingly natural.

The Pillow Book (1996), directed by Peter Greenaway, makes extensive use of split-screen techniques to demonstrate the concurrent states of various characters in the plot. This is accomplished by showing small images within a large frame or by shifting and scaling the size of the split-screen images, reinforcing the rhetorical concept of montage with traces of human intervention within the same frame. In Goltzius and the Pelican Company (2012), he also employs extensive digital compositing to create a post-modern sense of pictorial collage, deliberately utilising unfinished three-dimensional modelling effects to emphasise the three-dimensional nature of the space in which the scene is set, as well as a heavy reliance on floating subtitling effects to achieve the screen's occupation by text, a virtual unreality that reminds the viewer that cinema can be an extremely personal art form. Compositing and collage are based on the conceptual methods of pictorial art and art design, such as compositional 
proportions, perspective rules, colour shading, and layer design, and utilise digital film technology to create a digital hypothetical reality within the traditional image structure. On the other hand, the collage and fusion of disparate elements contribute to the narrative generation process, resulting in a distinctive stylized impression. From Who Framed Roger Rabbit (1988), in which fairy-tale characters are pasted into live-action films as central characters, to Sin City (2005) and Kill Bill (2003), in which digital animation is used as a narrative panel to supplement the cinematic representation or interpolate memories independently, using flexible animated scenes to distort, exaggerate, or intensify reality in response to imagination, memories, and This helps to differentiate it from the real world while enhancing the narrative's expressiveness and the visuality of the digital images, demonstrating the versatility of mimetic representation in the digital age. The richness and diversity of digital forms, as well as their generation and transformation, have become significant dimensions for people examining the presentation and fluid transformation of digital film imagery, and the realisation of non-realistic illusionary expressions through virtual imagery demonstrates a clear logic of narrative representation and the aesthetic pursuit of digital narrative.

\subsection{Anthropomorphism in Virtual Reality: The Experiential Nature of Physical Touch}

Jaron Lanier coined the term "virtual reality" in the 1980s, but its origins date all the way back to the French writer Aalto's description of theatre as "the hallucinatory nature of characters and objects in the theatre." Burdea and Coiffet regarded virtual reality as "a high-performance computer user interface that incorporates real-time simulation and interaction via multiple sensory channels. Sight, hearing, touch, smell, and taste are just a few of the sensory modalities "'. In other words, virtual reality can be thought of as the computer-aided creation of a new world that enables users to interact with it and emotionally immerse themselves in the sensory responses. Michael Heim defines virtual reality as "an immersive and interactive system based on computer data, with the primary characteristics of immersion, interaction, and information density." VR cinema is based on virtual reality technology, which combines computer graphics, simulation, and sensor technologies. It is then combined with augmented reality technology to create a new type of digital cinema that can be worn in a $360^{\circ}$ panoramic view. It enables multisensory interaction with the viewer within a $360^{\circ}$ panoramic space, eliciting the illusion of "immersion" and thus immersion. However, the artistry of cinema is still present in this type of tactile cinema, as cinema is concerned with narrative, whereas VR tactile images are concerned with developing interactive properties. It's also easy to see how the fusion of virtual reality and digital cinema could result in a narrative experience and storytelling that transcends interactivity, facilitated by new technologies.

Virtual reality films illustrate the use of panoramic visuals to create a more realistic environment, allowing the viewer to achieve a rather transparent and ultra-close view of the "absence of presence," to experience the reality of a virtual situation using realistic visuals similar to those found in everyday life, or to create an interactive "role-playing" environment that allows the viewer to experience a sense of reality in an interactive environment of physical touch. The unmatched audiovisual realism created by VR films enables the viewer to experience an extraordinary sense of immersion or empathy. The empathic effect of virtual reality is caused by the viewer's body being detached or displaced from their own into the scope of the image, or by using the virtual body as an avatar of the self, resulting in a somatic touch phenomenon, and by using the avatar's form to augment the viewer's real senses in order to experience the virtual reality world's narrative. In real life, people are already gaining experience with virtual reality through interaction with a variety of interactive interfaces, through the creation of interactive behavior patterns or virtual interaction effects with digital images in virtual space, through virtual bodies wandering through virtual worlds, indulging in them with a sense of wonder, appreciation, scrutiny, and critical aesthetic attitudes. The experience strengthens the audience's perceptual capacity for accurately and comfortably receiving sound, touch, tale, and conflict, and it also fosters a new understanding of the body's perception of experience and how to better recognize the interaction between film and audience in order to facilitate the production of physical touch. The viewer's body and the image body in the film create an intersubjective vision of the two bodies, or the image body in the film elicits an emotional resonance or interaction with the viewer, resulting in somatic touch; thus, somatic touch is the meaningful connection between the viewer's body and the film. In virtual reality cinema, the body creates new viewing experiences through the illusion of spatial displacement, and the illusionary reality of virtual reality enables our bodies to interact with and immerse themselves in the imitated content, so that the future of digital cinema "is no longer just about the bodies and fragments with which we represent ourselves in virtual space and play a role in it, but also about the body image we want to achieve in it." This requires an understanding of the bodily demands of 'somatic touch' on the viewer in aesthetic phenomena, as well as an aesthetic quest to consider people's embodied perceptions in an interactive narrative film environment from a bodily aesthetic perspective. 


\section{Filmography}

\begin{tabular}{|c|c|c|c|}
\hline No. & Film Title & Year of Release & Director \\
\hline 1 & A Space Odyssey & 1968 & Stanley Kubrick \\
\hline 2 & Close Encounters of the Third Kind & 1977 & Steven Spielberg \\
\hline 3 & Star Wars & $1977-2019$ & George Lucas \\
\hline 4 & Aliens & 1986 & James Cameron \\
\hline 5 & Who Framed Roger Rabbit & 1988 & Robert Zemeckis \\
\hline 6 & The Pillow Book & 1996 & Peter Greenaway \\
\hline 7 & Titanic & 1997 & James Cameron \\
\hline 8 & Lola rennt & 1998 & Tom Tykwer \\
\hline 9 & The Matrix & $1999 / 2003 / 2003$ & Laurence Wachowski \\
\hline 10 & The Lord of the Rings:The Fellowship of & 2001 & Peter Jackson \\
\hline 11 & the Ring & 2001 & Chris Columbus \\
\hline 12 & Harry Potter & 2003 & Quentin Tarantino \\
\hline 13 & Kill Bill:Vol.1 & 2003 & Ang Lee \\
\hline 14 & Hulk & 2004 & Roland Emmerich \\
\hline & The Day After Tomorrow & 2005 & $\begin{array}{c}\text { Frank Miller } \\
\text { Robert Rodriguez } \\
\text { Quentin Tarantino }\end{array}$ \\
\hline 15 & Sin City & & Gavin Hood \\
\hline 16 & Tsotsi & 2005 & Michael Bay \\
\hline 17 & Transformers & 2007 & David Fincher \\
\hline 18 & Jon Favreau \\
\hline 19 & Iron Man & 2008 & James Cameron \\
\hline 20 & Avatar & 2008 & Juan \\
\hline 21 & The Secret in Their Eyes & 2009 & J.Campanella \\
\hline 22 & The Avengers & 2009 & Jamed Whedon Wan \\
\hline 23 & Life of Pi & 2012 & Ang Lee \\
\hline 24 & Aquaman & 2013 & James Wan \\
\hline 25 & Goltzius and the Pelican Company & & \\
\hline
\end{tabular}

\section{References}

[1] Artaud, A. (2018). Theatre and its Double. Alma Books.

[2] Belton, J. (2002). Digital cinema: a false revolution. October, (100), 98-114.

[3] Bukatman, S. (1999). The artificial infinite: on special effects and the sublime. Alien Zone II, 249-276.

[4] Bonnard, M. (2016). La galaxie cinéma: migration et retour à la salle/Francesco Casetti, The Lumière Galaxy: Seven Key Words for the Cinema to Come, New York, Columbia University Press, 2015, 293 p. Cinémas: revue d'études cinématographiques/Cinémas: Journal of Film Studies, 26(2-3), 229-238.

[5] de Gorguette d'Argoeuves, T. (2010). Book Review: The Metaphysics of Virtual Reality-Michael Heim. ABAC Journal, 30(2).

[6] De Iulio, S. (2003). Lev Manovich, The Language of New Media. Cambridge, Massachusetts, London, England, The MIT Press, 2001, 354 p. Questions de communication, (4), 473-475.

[7] Furstenau, M. (2003). Cinema, Language, Reality: Digitization and the Challenge to Film Theory (Doctoral dissertation, McGill University)

[8] Ganz, A., \& Khatib, L. (2006). Digital cinema: The transformation of film practice and aesthetics. New Cinemas: Journal of Contemporary Film, 4(1), 21-36.
[9] Gaut, B. (2010). A philosophy of cinematic art. Cambridge University Press.

[10] Gunning, T. (1986). The cinema of attraction [s]: Early film, its spectator and the avant-garde. The Animation Studies Reader, $17-27$

[11] King, G. (2000). Spectacular Narratives: Contemporary Hollywood and Frontier Mythology. IB Tauris.

[12] King, J.. (2013) 'Zone, Ray. 3-D revolution: the history of modern stereoscopic cinema', CHOICE: Current Reviews for Academic Libraries. American Library Association CHOICE, p. 909.

[13] Matthews, P. (2001) 'The death of cinema: History, cultural memory and the digital Dark Age', Sight and Sound. LONDON: BRITISH FILM INST, pp. 32-32.

[14] Rodowick, D. N. (2009). The virtual life of film. Harvard University Press.

[15] Swale, A. D. (2015). Anime as Art: Digital Cinema and the Anime Aesthetic. In Anime Aesthetics (pp. 120-140). Palgrave Macmillan, London.

[16] Vexo, F. (2005). Virtual reality technology (2nd edn). Grigore C. Burdea and Philippe Coiffet, Wiley, New York, 2003. No. of pages: xvi+ 444. ISBN 0-471-36089-9. 